\title{
Evaluation of Thai Style Stretching Exercise on "Ruesi Dud Ton" on Physical Health and Oxidative Stress in Healthy Volunteer
}

\author{
${ }^{1,2}$ Jintanaporn Wattanathorn, ${ }^{3}$ Tasanee Boonterm, \\ ${ }^{1,2}$ Wipawee Thukhummee, ${ }^{1,2}$ Supaporn Muchimapura, \\ ${ }^{1,2}$ Panakaporn Wannanon, ${ }^{2}$ Sasalux Kaewbutra, ${ }^{3}$ Winai Chinnabut, \\ ${ }^{4}$ Kovit Chaisiwamongol and ${ }^{2}$ Prachaya Kaewkaen \\ ${ }^{1}$ Department of Physiology, Faculty of Medicine, \\ ${ }^{2}$ Integrative Complementary Alternative Medicine Research and Development Group, \\ ${ }^{3}$ Faculty of Education, \\ ${ }^{4}$ Department of Anatomy, Faculty of Medicine, \\ Khon Kaen University, Khon Kaen, 40002, Thailand
}

\begin{abstract}
Despite the health benefit reputation of Thai stretching exercise "Ruesi dud ton", no scientific evidence is available. Therefore, we aimed to determine the effect of Thai style stretching exercise on physical health and oxidative stress markers including Malondialdegyde (MDA) level and the activities of main scavenger enzymes including Superoxide Dismutase (SOD), Catalase (CAT) and Glutathione Peroxidase (GSH-Px). We had determined the effect of 2-month Ruesi dud ton exercise on physical health of healthy volunteer using battery test comprising of zig zag running, hand grip strength, 1 min abdominal curl up, 30 sec. push up and sit and reach tests. In addition, the body composition, BMI, skinfold thickness and the alteration of oxidative stress markers including the activities of SOD, CAT and GSH-Px enzymes and the level of MDA in serum were also evaluated every month throughout the experimental period and at 1 month after the cessation of exercise. Our data showed the enhanced capacity of zig zag running test in male practitioner more than female practitioner. We also found the elevation of scavenger enzymes such as SOD and GSH-Px and the reduction of MDA in female practitioner while the elevation of GSH-Px activity was the only parameter observed in male practitioner. Therefore, our results suggested that Thai style stretching exercise or Ruesi dud ton could enhance agility in male practitioner and improved oxidative stress homeostasis in female practitioner. Thai style stretching exercise can be implemented to the training program of male athletes. Moreover, it can also be implemented to improve oxidative stress in female who exposed to various risks of health disorders related to oxidative stress. However, further researches are still essential.
\end{abstract}

Keywords: Ruesi Dud Ton, Physical Health, Oxidative Stress, Superoxide Dismutase (SOD)

\section{INTRODUCTION}

Physical health is defined as a healthy body with good physical functions and with the competence to fulfill physical demands and challenges in daily life. It has been recognized as one of the key factors of quality of life. To be able to carry out daily tasks without undue fatigue or to enjoy leisure-time pursuits requires a certain degree of fitness of physical health. Therefore, improving and maintaining physical health are of concern for everyone.

Accumulative lines of evidence have revealed that the deterioration of various components of physical Khon Kaen, 40002, Thailand 
health were associated with the enhanced reactive oxygen species. It has been reported that the elevation of oxidative stress was associated with the decreased functional capacity of muscle (Stefania et al., 2004) which also includes the decreased muscle endurance and muscle strength (Reardon and Allen, 2009).

Recent findings have demonstrated that exercise can exert numerous favorable effects on general health (Warburton et al., 2006). Several lines of evidence show that the exercises involving stretching exercise incorporate with breathing practice such as Yoga and Taichi (Madanmohan et al., 2008; Wang, 2008) provide physical health benefit including cardiorespiratory function, muscle strength and posture control (Lee et al., 2009; Tran et al., 2001; Tsang and Hui-Chan, 2004). Moreover, they can also enhance antioxidant enzymes activities such as Superoxide Dismutase (SOD) and Glutathione Peroxidase (GSH-Px) while decrease Malondialdehyde (MDA) level (Agte et al., 2011; Hegde et al., 2011; Goon et al., 2009).

Ruesi dud ton or Thai style stretching exercise is one type of Thai traditional wisdom related to health care that can be used for health promotion, disease prevention and rehabilitation of some minor disorders. It consists of total 127 series of stretch exercise postures. However, only 15 basic postures are suitable for all ages and cover the exercise of all parts of the body from head to toe. While performing "Ruesi dud ton", the subject must also practice breathing exercises and meditation by focusing on breathing rhythm. Hence, the health benefits of "Ruesi dud ton" are increased body agility and muscle coordination, stimulated blood circulation and promotion of good concentration (Deewised, 1994). Based on the concept that subject must stretch muscle in accompany with breathing exercise during performance of Thai stretching exercise or Ruesi dud ton, we hypothesized that Thai stretching exercise might improve the physical health and oxidative stress in healthy volunteer. Since no scientific evidence is available, we aimed to determine the effect of Thai style stretching exercise on physical health and oxidative stress markers including Malondialdegyde (MDA) level and the activities of main scavenger enzymes including Superoxide Dismutase (SOD), Catalase (CAT) and Glutathione Peroxidase (GSH-Px).

\section{MATERIALS AND METHODS}

\subsection{Subjects}

Total 80 participants from Kaengkhro Wittaya School, Chaiyaphumi province were recruited to participate in this study. Inclusion criteria were (1) healthy male and female at the age of 14-18 years old (2) Body Mass Index (BMI) $18-24 \mathrm{~kg} \mathrm{~m}^{-2}$ (3) exercise less than 2 days per week (4) the physical activity is in mild to moderate level. Exclusion criteria included any history of cardiovascular disease, respiratory diseases, neuropsychological diseases, head injury, diabetes, cancer, alcohol addiction and anyone who smoked more than 10 cigarettes per day because all mentioned conditions could produce the disturbance of cognitive function. Individuals who are taking prescribed, non-prescribed drugs, or nutraceutical compounds known to influence the function of the nervous system were also exclude from this study. This study was approved by the Ethical Committee of the Faculty of Medicine at Khon Kaen University. Prior to investigation, each volunteer provided informed consent and completed the medical health questionnaire. Participants were also screened for physical health by a physician in order to assure healthy condition.

\subsection{Procedure and Intervention}

This study was a pilot study conducted as 8-week, double-blind, randomized trial. A random list of numbers was generated by computer. After being randomly assigned to either control or exercise groups. Since the study is the preliminary study of clinical trial, the number of the sample size can be a small number at least 12 per group (Julious, 2005). All participants were assessed baseline data about health related physical fitness including body composition, anthopometry, muscular strength, muscular endurance and flexibility and oxidative stress markers including, Malondialdehyde (MDA) level and the activities of scavenger enzymes including Superoxide Dismutase (SOD), Catalase (CAT) and Glutathione Peroxidase (GSH-Px). Then, all parameters mentioned earlier were determined at 1 and 2 months of treatment. Staffs who involved in the collection of the study's endpoints were instructed to follow a rigorous protocol. The review of compliance with intervention was performed independently by the investigators. Subjects were asked to call the study center if they experienced any health problems during the 60-day study period. At the end of the study, they were also asked about adverse events.

\subsection{Outcome Measures}

\subsubsection{Physical Health}

In this study, we focused on the determination of some aspects of physical health including muscle endurance, 
muscle strength, flexibility, postural control, body composition and anthropometry. Muscle endurance, muscle strength, flexibility and postural control were assessed using battery test as described following:

\subsection{Zig Zag Running Test}

This test was used to determine the speed, agility and postural control. According to this test, four cones placed on the corners of a rectangle 10 by 16 feet, with one more cone placed in the centre. If the cones are labeled 1-4 around the rectangle going along the longer side first and the centre cone is $\mathrm{C}$, the test begins at 1 , then to $\mathrm{C}, 2,3, \mathrm{C}, 4$, then back to 1 . Each subject has to perform this test as soon as possible.

\subsection{Hand Grip Strength}

In order to assess the maximum force that hand muscles can exert when they contract, the grip strength test was performed using hand grip dynamometer. Each subject has to use their hands to apply as much grip pressure as possible on dynamometer and the strength was recorded. Each subject must repeat the test 3 times and the highest value was use as index for the performance.

\subsection{Abdominal Curl Up Test}

This test was used to assess the strength and endurance of abdominal muscle. According to this test, the subject must lie on a mat with knees flexed and feet approximately 12 inches from their buttocks. A partner assisted by anchoring the feet to the ground. The arms were held flat across the chest, with the hands placed on opposite shoulders. The subject must raise the trunk, keeping the arms in position, curling up to touch their elbows to thighs and then lowered back to the floor so that the shoulder bladed (upper back) touch the floor. The maximum number of sit ups performed in one minute is recorded.

\subsection{0 sec. Push Up Test}

This test was applied to evaluate the strength and endurance of upper body. Subject must lie down on a mat or soft flooring with your hands shoulder-width apart and arms fully extended and your legs straight with feet together while keeping back straight and flat and head up (eyes facing forward). Subject must bend the elbow to lower the body until the elbows reach a $90^{\circ}$ angle (chest should be approximately 3-4 inches from the floor), then return the body up to the start position. Subject must repeat as much as possible within $30 \mathrm{sec}$.

\subsection{Sit and Reach Test}

This test is a common test for measuring flexibility particularly the flexibility of the lower back and hamstring muscles. This test involves sitting on the floor with legs stretched out straight ahead. Shoes should be removed. The soles of the feet are placed flat against the box. Both knees should be locked and pressed flat to the floor-the tester may assist by holding them down. With the palms facing downwards and the hands on top of each other or side by side, the subject reaches forward along the measuring line as far as possible.

\subsection{Body Composition and Anthropometry Measurement}

Body weight was measured to the nearest $0.05 \mathrm{~kg}$ using a digital scale and height was measured to the nearest $0.1 \mathrm{~cm}$ using a wall-mounted stadiometer while the subjects were standing without shoes in light clothes. BMI was calculated as weight $(\mathrm{kg})$ divided by height (m). The body mass and body composition (total water, muscle mass, visceral fat and body fat) were assessed by bioelectrical impedance (TANITA BODY Composition Analyzer Mode BC-543). In all subjects, subcutaneous skin folds from selected sites including biceps, triceps, subscapular and suprailiac were measured in triplicate, by the same trained observer. Measurements were made on the right hand side of the body using a Holtain caliper according to methods described in the Anthropometric Standardization Reference Manual (Lohman et al., 1988).

\subsection{Evaluation of Oxidative Stress Markers}

Oxidative stress markers changes were indirectly assessed using the level of Malondialdehyde (MDA) and the activities of scavenger enzymes including Superoxide Dismutase (SOD), Catalase (CAT) and Glutathione Peroxidase (GSH-Px) as indices. MDA was estimated by determining the accumulation of Thiobarbituric Acid Reactive Substances (TBARS) (Wattanathorn et al., 2012) in the nerve homogenate whereas the activities of Superoxide Dismutase (SOD), Catalase (CAT) and Glutathione Peroxidase (GSH-Px) were determined by recording the ability to inhibit cytochrome $\mathrm{C}$, the rate of decrease in $\mathrm{H}_{2} \mathrm{O}_{2}$ and the amount of reduced Nicotinamide Adenine Dinucleotide Phosphate (NADPH) oxidized per minute respectively (Jittiwat et al., 2009).

\subsection{Statistical Analysis}

All data were expressed as mean \pm S.E.M. Subgroup comparisons between control and exercise group both in male and female were made using Analysis Of Variance (ANOVA). In addition, the comparison between the 
interested parameters of baseline data and the interested parameters at 1 and 2 months after intervention were performed using pair Student's t-test. Statistical significance was set at $\mathrm{p}$-value $<0.05$.

\section{RESULTS}

\subsection{Demographic Data of Participants}

The demographic data of all participants in this study were shown in Table 1. It was found that no significant difference in age, arterial blood pressure, respiratory function, blood sugar and cholesterol. Therefore, these data also confirmed that all data which were influencing on the function of learning and memory did not show the significant difference.

\subsection{Effect of Thai style stretching exercise, Ruesi dud ton, on physical health}

Table 2 showed that no significant difference on any parameters was observed prior to the exercise intervention. Our data showed that at 1-month of exercise intervention, the muscle masses of male practitioners were increased while the body fat decreased (p-value $<0.05$ and 0.01 respectively; compared to male control group). However, these significant changes disappeared when the intervention duration increased further to 2 months. In addition, it was found that male practitioner enhanced capability to perform zig zag running ( $p$-value $<0.05$; compared to male control group).

\subsection{Effect Ruesi Dud Ton on Oxidative Stress Markers}

Figure 1-4 showed the effect of Ruesi dud ton on the activities of Superoxide Dismutase (SOD), Catalase (CAT) and Glutathione Peroxidase (GSH-Px) and the level of Malondialdehyde (MDA) level. Our results showed that no significant changes of any parameters mentioned earlier before the intervention (baseline data). It was also found that after 1-month of Ruesi dud ton intervention, the serum of both male and female practitioners showed the elevation of GSH-Px activity ( $\mathrm{p}$-value $<0.05$; compared to male control group; $\mathrm{p}$ value $<0.05$; compared to female control group). In addition, the elevation of serum SOD activity in female practitioner was also observed (p-value $<0.05$; compared to female control group) whereas no other changes were observed.

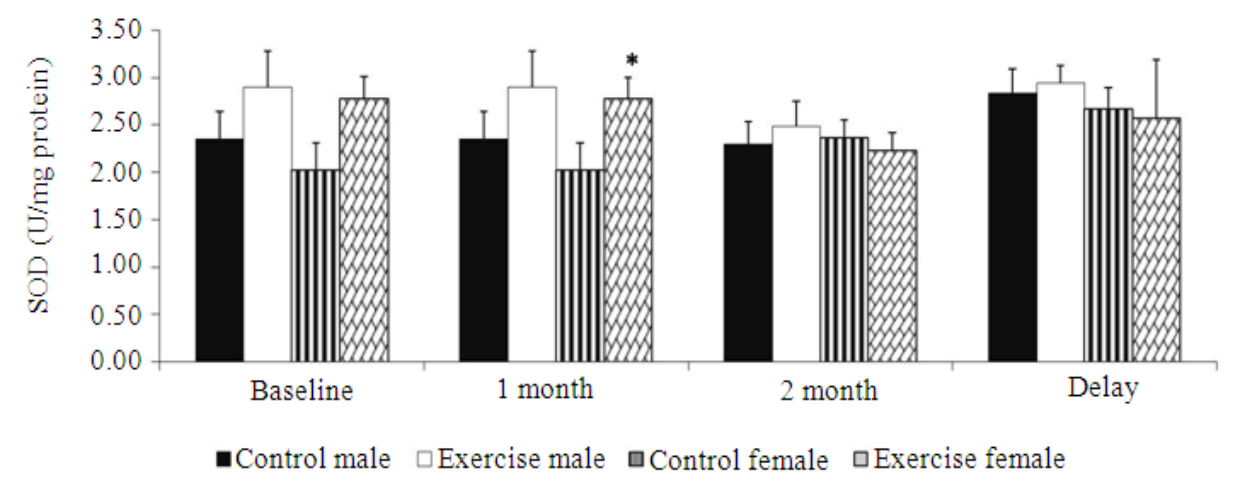

Fig. 1. Effect of Ruesi dud ton on superoxide dismutase enzyme activity. ( $n=20$ /group) Data were expressed as mean \pm SEM (*pvalue $<0.05$; compared to female control group)

Table 1. Demographic data of subjects, $(n=20$ /group) Data were presented as mean \pm S.E.M

\begin{tabular}{lrrrc}
\hline Baseline data & Control MALE & Exercise male & Control female & Exercise female \\
\hline Aged (years) & $14.95 \pm 5.150$ & $17.05 \pm 0.830$ & $16.65 \pm 0.490$ & $16.95 \pm 0.7800$ \\
Heart Rate (bpm) & $79.06 \pm 13.45$ & $81.45 \pm 22.03$ & $90.25 \pm 9.400$ & $91.32 \pm 10.72$ \\
Systolic blood pressure (mmHg) & $120.61 \pm 12.62$ & $118.80 \pm 27.07$ & $113.10 \pm 10.67$ & $110.68 \pm 8.49$ \\
Diastolic blood pressure (mmHg) & $65.33 \pm 8.260$ & $65.55 \pm 12.92$ & $65.45 \pm 8.540$ & $66.79 \pm 8.220$ \\
Mean arterial blood pressure (mmHg) & $75.38 \pm 27.08$ & $83.30 \pm 12.94$ & $81.33 \pm 7.910$ & $81.42 \pm 7.700$ \\
Respiratory rate (breaths/min) & $22.89 \pm 11.59$ & $18.30 \pm 1.630$ & $20.45 \pm 2.520$ & $21.53 \pm 2.520$ \\
Blood sugar (mg/dl) & $78.75 \pm 1.690$ & $79.30 \pm 1.750$ & $79.95 \pm 2.070$ & $79.05 \pm 2.160$ \\
Cholesterol /mg)dl) & $141.90 \pm 3.460$ & $139.00 \pm 3.320$ & $137.25 \pm 3.320$ & $142.37 \pm 3.32$ \\
\hline
\end{tabular}


Table 2. Effect of Ruesi dud ton on physical health including muscle endurance, muscle strength, flexibility, postural control, body composition and anthropometry. Muscle endurance, muscle strength, flexibility and postural control. ( $n=20$ /group) Data were expressed as mean \pm SEM ( ${ }^{\text {a,aa }} \mathrm{p}$-value $<0.05 ; .01$; compared to male control group)

\begin{tabular}{|c|c|c|c|c|c|}
\hline Parameter & Group & Baseline & 1 month & 2 months & Delay \\
\hline \multirow[t]{4}{*}{ Zigzag run (sec) } & Control Male & $24.11+0.27$ & $21.05+0.56$ & $22.28+0.62$ & $24.11 \pm 0.27$ \\
\hline & Exercise Male & $23.15+0.36$ & $20.40+0.59$ & $19.74+0.55^{\mathrm{a}}$ & $23.15 \pm 0.36$ \\
\hline & Control Female & $26.15 \overline{+} 0.55$ & $25.21 \overline{+} 0.66$ & $22.30 \mp 0.58$ & $25.75 \mp 0.35$ \\
\hline & Exercise Female & $25.75 \pm 0.35$ & $24.95 \pm 0.56$ & $22.74 \pm 0.55$ & $24.74 \pm 0.53$ \\
\hline \multirow{4}{*}{$\begin{array}{l}\text { Left Grip strength } \\
\text { test (kg.) }\end{array}$} & Control Male & $36.78 \pm 1.10$ & $37.50 \pm 1.46$ & $37.72 \pm 1.29$ & $36.89 \pm 0.98$ \\
\hline & Exercise Male & $37.65 \pm 2.00$ & $39.18 \pm 1.92$ & $40.00 \mp 1.24$ & $39.75 \pm 1.40$ \\
\hline & Control Female & $22.23+0.79$ & $22.38+0.78$ & $25.15+2.62$ & $22.69+0.89$ \\
\hline & Exercise Female & $22.45 \pm 0.66$ & $22.19 \pm 0.65$ & $23.11 \mp 0.84$ & $22.32 \pm 0.75$ \\
\hline \multirow{4}{*}{$\begin{array}{l}\text { Right Grip strength } \\
\text { test (kg.) }\end{array}$} & Control Male & $39.01 \pm 1.37$ & $40.02 \pm 1.41$ & $38.17 \overline{+} 1.40$ & $38.83+1.16$ \\
\hline & Exercise Male & $38.38 \pm 1.62$ & $40.65 \pm 1.69$ & $39.85 \pm 1.15$ & $40.25 \pm 0.69$ \\
\hline & Control Female & $25.28 \pm 0.92$ & $25.45 \pm 0.90$ & $28.31+2.39$ & $25.85 \pm 0.85$ \\
\hline & Exercise Female & $25.20 \pm 0.63$ & $25.26 \pm 0.65$ & $25.58 \pm 0.69$ & $25.32 \pm 0.89$ \\
\hline \multirow{4}{*}{$\begin{array}{l}1 \text { minute abdominal } \\
\text { curl (times) }\end{array}$} & Control Male & $33.11+1.30$ & $37.83+2.01$ & $41.11+1.21$ & $34.00+1.01$ \\
\hline & Exercise Male & $33.7+0.94$ & $35.90 \pm 1.03$ & $38.80 \pm 1.46$ & $34.40 \pm 1.13$ \\
\hline & Control Female & $21.4 \overline{7} \pm 1.50$ & $21.84 \pm 1.54$ & $25.29 \pm 1.08$ & $23.11 \pm 0.91$ \\
\hline & Exercise Female & $23.89 \pm 1.10$ & $24.91 \pm 1.00$ & $25.59 \pm 0.80$ & $22.63 \pm 0.85$ \\
\hline \multirow{4}{*}{$\begin{array}{l}30 \text { second push-ups } \\
\text { (times) }\end{array}$} & Control Male & $25.16 \pm 1.90$ & $30.50 \pm 2.34$ & $29.56 \pm 1.02$ & $26.33+1.50$ \\
\hline & Exercise Male & $25.65 \pm 1.75$ & $27.20+1.57$ & $27.30+1.89$ & $26.45 \pm 1.74$ \\
\hline & Control Female & $12.15 \pm 0.82$ & $12.57 \pm 0.86$ & $15.93 \pm 0.59$ & $14.28 \pm 0.65$ \\
\hline & Exercise Female & $14.20 \pm 0.59$ & $14.85 \pm 0.61$ & $15.06 \pm 0.85$ & $12.89 \pm 0.57$ \\
\hline \multirow{4}{*}{$\begin{array}{l}\text { Flexibility test } \\
\text { (centimeters) }\end{array}$} & Control Male & $10.82 \pm 1.19$ & $11.26 \pm 1.11$ & $13.76+0.99$ & $10.82 \pm 1.19$ \\
\hline & Exercise Male & $11.06 \pm 1.43$ & $11.50+1.44$ & $16.07 \pm 2.14$ & $11.07 \pm 1.43$ \\
\hline & Control Female & $9.72 \pm 1.33$ & $9.72 \pm 1.39$ & $13.12 \pm 1.14$ & $9.74 \pm 1.07$ \\
\hline & Exercise Female & $10.01 \pm 1.00$ & $10.32 \pm 0.97$ & $13.82 \pm 1.09$ & $10.25 \pm 1.34$ \\
\hline \multirow[t]{4}{*}{ Visceral fat (\%) } & Control Male & $2.39 \pm 2.43$ & $2.33+2.02$ & $6.11+15.45$ & $2.29 \pm 1.77$ \\
\hline & Exercise Male & $2.45+3.41$ & $2.53+3.56$ & $5.08+12.16$ & $2.64+3.84$ \\
\hline & Control Female & $4.86+12.21$ & $6.03+13.11$ & $1.64+1.01$ & $1.64+1.01$ \\
\hline & Exercise Female & $3.21 \pm 3.31$ & $2.53 \pm 2.01$ & $2.43 \pm 2.03$ & $2.43 \pm 1.79$ \\
\hline \multirow[t]{4}{*}{ Body fat (\%) } & Control Male & $12.08+5.96$ & $20.25 \pm 16.10$ & $13.65 \pm 6.67$ & $13.19 \pm 5.86$ \\
\hline & Exercise Male & $11.23 \pm 6.25$ & $9.66+2.99^{\mathrm{aa}}$ & $12.32+2.76$ & $10.78+3.14$ \\
\hline & Control Female & $22.69 \pm 6.24$ & $24.72 \pm 9.84$ & $24.56+3.47$ & $24.16+3.45$ \\
\hline & Exercise Female & $26.16 \pm 6.24$ & $28.73 \pm 7.81$ & $27.14 \pm 4.72$ & $26.83 \pm 4.82$ \\
\hline \multirow[t]{4}{*}{ Total body water (\%) } & Control Male & $64.38+4.40$ & $62.93+5.17$ & $63.11+4.10$ & $62.18+6.09$ \\
\hline & Exercise Male & $64.25+4.69$ & $64.53+2.02$ & $64.24+2.01$ & $64.91+2.40$ \\
\hline & Control Female & $54.34 \pm 4.69$ & $54.02 \pm 4.62$ & $55.21 \pm 2.55$ & $55 . \overline{30}+2.54$ \\
\hline & Exercise Female & $54.07 \pm 4.57$ & $53.76 \pm 4.47$ & $51.12 \pm 6.16$ & $53.59+3.52$ \\
\hline \multirow[t]{4}{*}{ Muscle mass (kg) } & Control Male & $46.13+13.72$ & $41.66 \pm 18.18$ & $44.59+9.20$ & $47.86+6.90$ \\
\hline & Exercise Male & $49.44+13.06$ & $50.51+4.00^{\mathrm{a}}$ & $44.18+18.21$ & $48.03+8.38$ \\
\hline & Control Female & $35.01 \pm 4.51$ & $34.80+4.52$ & $29.63+12.75$ & $34.61 \pm 2.42$ \\
\hline & Exercise Female & $34.66 \pm 9.11$ & $34.53 \pm 9.10$ & $34.29 \pm 11.91$ & $35.70 \pm 3.37$ \\
\hline Body mass index & Control Male & $20.52+2.39$ & $20.57 \pm 1.82$ & $20.46+1.56$ & $20.60+1.82$ \\
\hline \multirow{3}{*}{$\left(\mathrm{kg} /\right.$ meters $\left.^{2}\right)$} & Exercise Male & $21.19+3.70$ & $20.36+1.28$ & $20.47 \pm 1.42$ & $20.42+1.53$ \\
\hline & Control Female & $21.67+6.80$ & $21.55 \pm 6.80$ & $19.24+1.85$ & $19.30+1.88$ \\
\hline & Exercise Female & $20.00 \pm 3.10$ & $20.69 \pm 3.36$ & $20.70 \pm 2.97$ & $20.64 \pm 2.88$ \\
\hline Biceps skin fold & Control Male & $7.39+3.18$ & $6.41+1.61$ & $4.62+4.01$ & $4.36+3.68$ \\
\hline \multirow[t]{3}{*}{ thickness (millimeters) } & Exercise Male & $7.48+2.43$ & $6.57 \pm 1.52$ & $5.32+4.02$ & $4.97+4.59$ \\
\hline & Control Female & $11.75+3.42$ & $9.43+4.13$ & $5.16+4.79$ & $5.86+4.50$ \\
\hline & Exercise Female & $13.87 \pm 5.53$ & $11.06 \pm 5.37$ & $7.27 \pm 5.85$ & $8.05+5.66$ \\
\hline Triceps skin fold & Control Male & $12.14+5.38$ & $10.32 \pm 4.40$ & $6.77 \pm 5.86$ & $7.12 \pm 7.02$ \\
\hline \multirow[t]{3}{*}{ thickness (millimeters) } & Exercise Male & $13.22+5.16$ & $9.75+3.00$ & $7.59+5.05$ & $7.58+5.58$ \\
\hline & Control Female & $19.40+4.77$ & $17.34+5.76$ & $9.19+6.81$ & $9.90+6.96$ \\
\hline & Exercise Female & $19.01 \pm 6.04$ & $15.58 \pm 5.59$ & $9.99 \pm 7.76$ & $9.91+7.41$ \\
\hline Suprailiac skin fold & Control Male & $13.19+4.80$ & $11.60 \pm 4.36$ & $6.54+5.07$ & $6.53+5.48$ \\
\hline \multirow[t]{3}{*}{ thickness (millimeters) } & Exercise Male & $13.05+7.43$ & $10.61+2.97$ & $13.28+23.49$ & $6.47+4.61$ \\
\hline & Control Female & $20.00+8.53$ & $15.80+8.02$ & $8.74+6.98$ & $7.81+7.17$ \\
\hline & Exercise Female & $19.47 \pm 7.65$ & $15.41 \pm 8.53$ & $10.18 \pm 7.66$ & $9.91 \pm 7.77$ \\
\hline Subscapular skin fold & Control Male & $12.41+4.71$ & $11.43+4.48$ & $7.54+7.15$ & $7.10+6.53$ \\
\hline \multirow[t]{3}{*}{ thickness (millimeters) } & Exercise Male & $11.65+3.64$ & $9.71+1.68$ & $7.69+4.64$ & $10.05+7.21$ \\
\hline & Control Female & $20.90+5.07$ & $15.45 \pm 6.84$ & $7.83+8.24$ & $7.81+8.22$ \\
\hline & Exercise Female & $20.33 \pm 7.14$ & $15.93 \pm 7.07$ & $6.78 \pm 7.93$ & $9.70 \pm 8.48$ \\
\hline
\end{tabular}




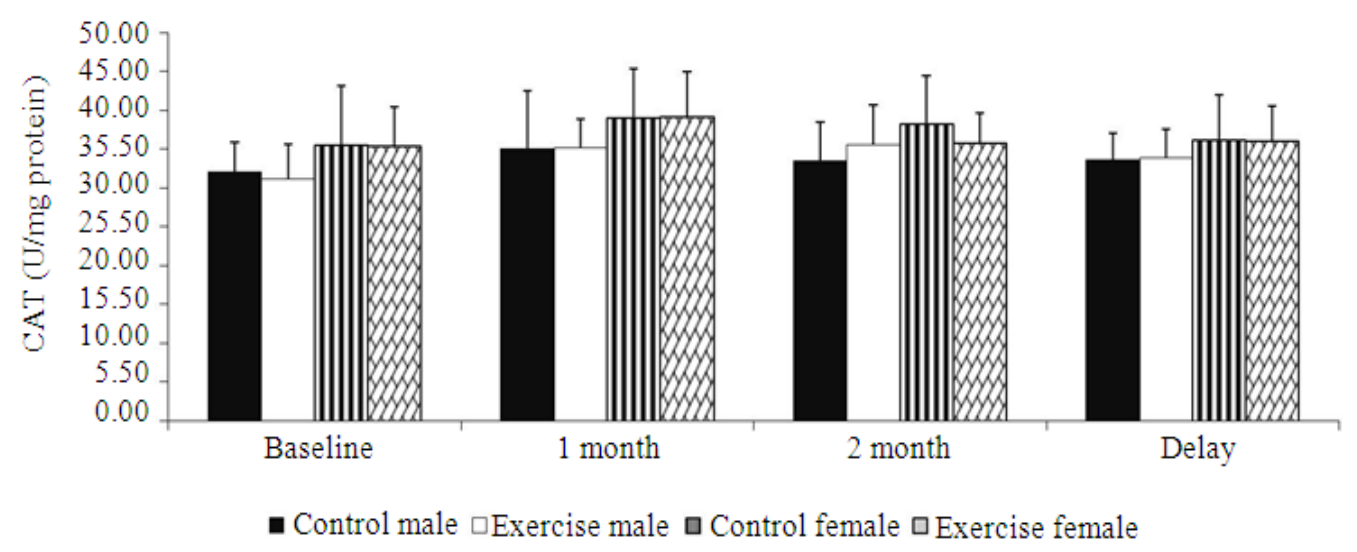

Fig. 2. Effect of Ruesi dud ton on catalase enzyme activity. ( $n=20$ /group) Data were expressed as mean \pm SEM

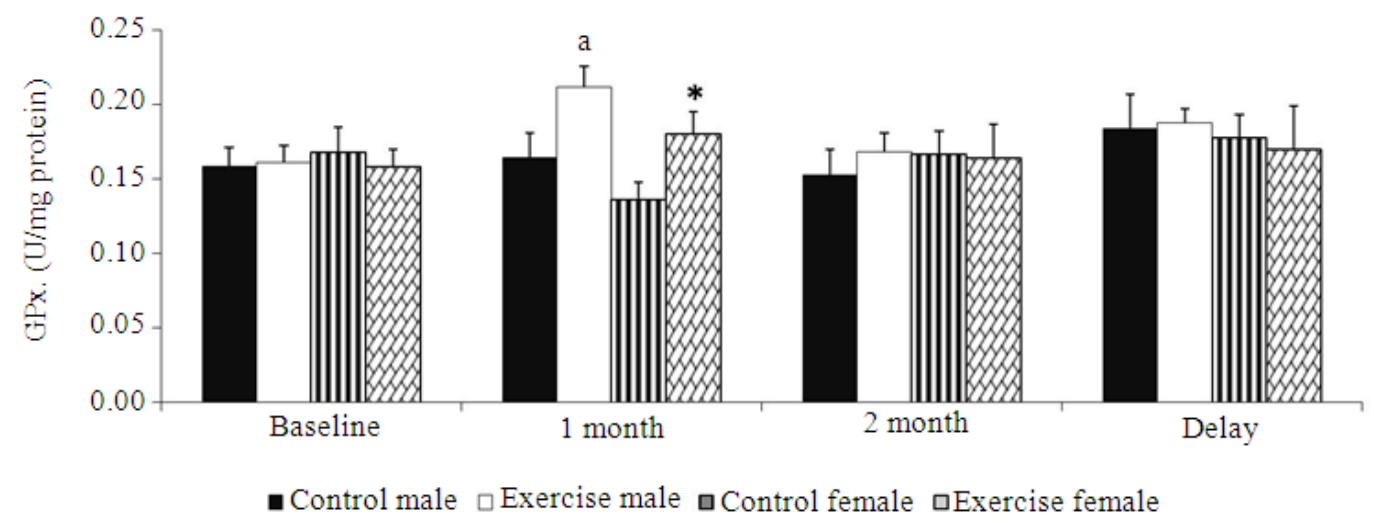

Fig. 3. Effect of Ruesi dud ton on glutathione peroxidase enzyme activity. ( $n=20 /$ group) Data were expressed as mean \pm SEM ( ${ }^{a},{ }^{*} p$ value $<0.05$; compared to male and female control group)

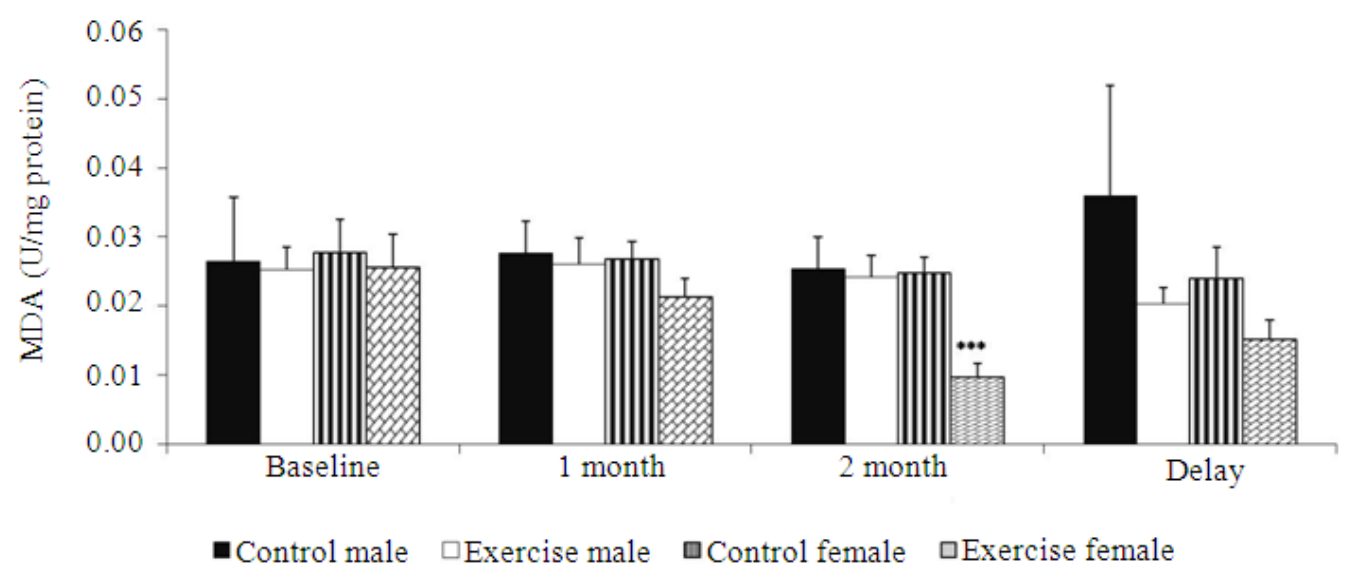

Fig. 4. Effect of on Ruesi dud ton on malondialdehyde level. ( $\mathrm{n}=20$ /group) Data were expressed as mean \pm SEM (*** $\mathrm{p}$ value $<0.001$; compared to male and female control group) 
At 2-month intervention period, only the decreased serum MDA level of female practitioner was observed ( $p$ value $<0.05$; compared to female control group). Unfortunately no other significant changes were observed.

\section{DISCUSSION}

The present study demonstrates the beneficial effect of an 8-week Thai style stretching exercise, an active stretching exercise, on zig zag running test which indicates the improved agility, speed and postural control. Our results were in agreement with previous study which demonstrated the beneficial effect of active stretching exercise like yoga on agility (Cowen and Adams, 2005; Gaurav, 2011; Liu et al., 2010). The enhanced agility might be associated with the joint proprioceptive acuity and dynamic standing balance control (Tsang and Hui-Chan, 2004). It was also found that Thai style stretching exercise also altered body composition at 1 month intervention period. However, this change disappeared when the intervention increased. The possible explanation for this change may attribute to the other factors such as food and physical activity which also play the crucial role on the body composition and these effects exerted greater impact $\mathrm{n}$ body composition than Thai style stretching exercise.

Interestingly, Thai style stretching exercise also induced the enhanced activities of GSH-Px in both male and female together with the enhanced SOD activity in female practitioner after 1 month of intervention. However, no significant reduction of MDA level was observed. It has been reported that exercise enhances the oxygen uptake both at the whole body and cellular level. Most of the oxygen is utilized in mitochondria for oxidative phosphorylation and reduced to water. During this process, approximate $2-5 \%$ of oxygen supply is converted to superoxide anion radical, hydrogen peroxide and hydroxyl radical. Though hydrogen peroxide and other peroxide are not radicals, they are very active. All of the mentioned molecules are regarded as Reactive Oxygen Species (ROS). The elevation of the ROS induced by exercise might beyond the capacity of scavenger enzymes (Ji, 2003). Therefore, no reduction of MDA was observed during this period. During 2-month exercise duration, it was found that the serum MDA level especially in female practitioner without changes on scavenger enzymes activities. The possible explanation might be related to the buffering capacity of endogenous non-enzymatic antioxidant system such as Glutathione (GSH). It has been reported that GSH can be synthesized at liver and during prolonged exercise (Lu et al., 1994), the efflux of GSH was elevated and might scavenge the enhanced ROS induced by exercise resulting in the reduction of MDA level. Moreover, it was found that estrogen could enhance mitochondrial function resulting in the decreased reactive oxygen species production (Stirone et al., 2005). In addition, the enhanced GSH-Px and SOD were also observed (Massafra et al., 2000; Shahrokhi et al., 2012). Since estrogen can decrease the oxidative stress formation, therefore the reduction of MDA at 2-month intervention period might also be attributed to the decreased oxidative stress formation induced by estrogen.

It has been reported agility is under the influence of many factors including strength power, neuromuscular control and flexibility. Therefore, the enhanced agility might be attributed to the difference of various factors mentioned above. However, the precise underlying mechanisms are still further exploration.

\section{CONCLUSION}

This study has clearly demonstrated that Thai style stretching exercise provide health benefit to enhance agility, the important motor skill for athletes, in male. Moreover, it also decreases oxidative stress, a key factor in the pathophysiology of numerous disorders, especially in female. Therefore, it can be implemented to the training program of male athletes. Moreover, it can also be implemented to improve oxidative stress in female who exposed to various risks of health disorders related to oxidative stress. However, further researches are still essential.

\section{ACKNOWLEDGEMENT}

This study was supported by Thai Health Foundation and Integrative Complimentary Alternative Medicine Research and Development Group, Khon Kaen University.

\section{REFERENCES}

Agte, V.V., M.U. Jahagirdar and K.V. Tarwadi, 2011. The effects of Sudarshan Kriya Yoga on some physiological and biochemical parameters in mild hypertensive patients. Indian J. Physiol Pharmacol., 55:183-187. PMID: 22319901

Cowen, V. and T. Adams, 2005. Physical and perceptual benefits of yoga asana practice: Results of a pilot study. J. Bodywork Movem. Ther., 9: 211-219. DOI: 10.1016/j.jbmt.2004.08.001 
Deewised, K., 1994. Background of thai massage. Proceedings of the Thai Massage for Public Health Officers Workshop Report, (TMPHOWR' 94), The War Veterans Organization of Thailand, Bangkok, pp: 6-7.

Gaurav, V., 2011 Effects of hatha yoga training on the health-related physical fitness. Int. J. Sports Sci. Eng., 5: 169-173.

Goon, J.A., A.H. Aini, M. Musalmah, M.Y. Anum and W.M. Nazaimoon et al., 2009. Effect of Tai Chi exercise on DNA damage, antioxidant enzymes and oxidative stress in middle-age adults. J. Phys. Act. Health, 6: 43-54. PMID: 19211957

Hegde, S.V., P. Adhikari, S. Kotian, V.J. Pinto and S. D'Souza et al., 2011. Effect of 3month yoga on oxidative stress in type 2 diabetes with or without complications: A controlled clinical trial. Dia. Care., 34: 2208-2210. DOI: 10.2337/dc10-2430

Ji, L.L., 2003 Free radicals and exercise: Implication in health and fitness. J. Exerc. Sci. Fit., 1: 15-22.

Jittiwat, J., J. Wattanthorn, S. Muchimapura and C. Bunchonglikikul, 2009. Porcine brain extract attenuates memory impairments induced by focal cerebral ischemia. Am. J. Applied Sci., 6: 16621668. DOI: 0.3844/ajassp.2009.1662.1668

Julious, S.A., 2005. Two-sided confidence intervals for the single proportion: comparison of seven methods. Stat. Med., 24: 3383-3384. DOI: 10.1002/sim.2164

Lee, M.S, E.N. Lee, E. Ernst, 2009. Is tai chi beneficial for improving aerobic capacity? A systematic review. Br. J. Sports Med., 43: 569-573. DOI: 10.1136/bjsm.2008.053272

Liu, J., B. Li and R. Schnider, 2010. Effects of Tai Chi Training on improving physical function in patients with coronary heart diseases. J. Exerc. Sci. Fit., 8: 78-84. DOI: 10.1016/S1728-869X(10)60012-3

Lohman, T.G., A.F. Roche and R. Martorell, 1988. Anthropometric Standardization Reference Manual. 1st Edn., Human Kinetics Publishers, Champaign, IL., ISBN-10: 0873221214, pp: 184.

Lu, Q.L., A.M. Hanby, M.A.N. Hajibagheri, S.E. Gschmeissner and P.J. Lu et al., 1994. Bcl-2 protein localizes to the chromosomes of mitotic nuclei and is correlated with the cell cycle in cultured epithelial cell lines. J. Cell Sci., 107: 363-371.

Madanmohan, M.S.K., S. Balakrishnan, M. Gopalakrishnan and E.S. Prakash, 2008. Effect of six weeks yoga training on weight loss following step test, respiratory pressures, handgrip strength and handgrip endurance in young healthy subjects. Indian J. Physiol. Pharmacol., 52: 164-170. PMID: 19130860
Massafra, C., D. Gioia, C. De Felice, E. Picciolini and V. De Leo et al., 2000. Effects of estrogens and androgens on erythrocyte antioxidant superoxide dismutase, catalase and glutathione peroxidase activities during the menstrual cycle. J. Endocrinol., 167: 447-52. DOI: 10.1677/joe.0.1670447

Reardon, T.F. and D.G. Allen, 2009. Iron injections in mice increase skeletal muscle iron content, induce oxidative stress and reduce exercise performance. Exp. Physiol., 94: 720-30. DOI: 10.1113/expphysiol.2008.046045

Shahrokhi, N., M.K. Haddad, S. Joukar, M. Shabani and Z. Keshavarzi et al., 2012. Neuroprotective antioxidant effect of sex steroid hormones in traumatic brain injury. Pak. J. Pharm. Sci., 25: 21925. PMID: 22186333

Stefania, F., T. Pietrangelo, R. Bellomo, D. Sagnella and S. Belia, 2004 The Relationship between oxidative stress and the functional capacity of skeletal muscle. Basic. Applied Myol., 14: 33-36.

Stirone, C., S.P. Duckles, D.N. Krause and V. Procaccio, 2005. Estrogen increases mitochondrial efficiency and reduces oxidative stress in cerebral blood vessels. Mol. Pharmacol., 68: 959-965. DOI: 10.1124/mol.105.014662

Tran, M.D., R.G. Holly, J. Lashbrook and E.A. Amsterdam, 2001. Effects of Hatha Yoga Practice on the Health-Related Aspects of Physical Fitness. Prev. Cardiol., 4: 165-170. PMID: 11832673

Tsang, W.W. and C.W. Hui-Chan, 2004. Effects of exercise on joint sense and balance in elderly men: Tai Chi versus golf. Med. Sci. Sports Exerc., 36: 658-667. PMID: 15064594

Wang, Y., 2008. Tai Chi exercise and the improvement of mental and physical health among college students. Med. Sport Sci., 52: 135-145. DOI: 10.1159/000134294

Warburton, D.E., C.W. Nicol, S.S. Bredin, 2006. Health benefits of physical activity: The evidence. Can Med. Ass. J., 174: 801-809. DOI: 10.1503/cmaj.051351

Wattanathorn, J., S. Muchimapura, T. Tong-Un, N. Saenghong and W. Thukhum-Mee et al., 2012. Positive modulation effect of 8-week consumption of Kaempferia parviflora on health-related physical fitness and oxidative status in healthy elderly volunteers. Evidence-Based Complementary Alternative Med. DOI: 10.1155/2012/732816 